\title{
Deciliter per Gram
}

National Cancer Institute

\section{Source}

National Cancer Institute. Deciliter per Gram. NCI Thesaurus. Code C69072.

A dose calculation unit expressed in deciliter(s) per gram. 